\title{
Rheological Characterization of Polysaccharide-Poly(ethylene glycol) Star Copolymer Hydrogels
}

\author{
Nori Yamaguchi ${ }^{\dagger} \ddagger$, Byeong-Seok Chae $§$, Le Zhang ${ }^{\dagger} \ddagger$, Kristi L. Kiick ${ }^{\dagger} \ddagger$, and Eric M. Furst ${ }^{*}, \S$ \\ Department of Materials Science and Engineering, Delaware Biotechnology Institute, and \\ Department of Chemical Engineering, University of Delaware, Newark, Delaware 19716
}

\begin{abstract}
Binding interactions between low molecular weight heparin (LMWH) and heparin-binding peptides (HBP) have been applied as a strategy for the assembly of hydrogels that are capable of sequestering growth factors and delivering them in a controlled manner. In this work, the assembly of four-arm star poly(ethylene glycol) (PEG)-LMWH conjugate with PEG-HBP conjugates has been investigated. The interactions between LMWH and the heparin-binding regions of antithrombin III (ATIII) or the heparin interacting protein (HIP) have been characterized via heparin affinity chromatography and surface plasmon resonance (SPR); results indicate that the two peptides have slightly different affinities for heparin and LMWH, and bind LMWH with micromolar affinity. Solutions of the PEG-LMWH and of mixtures of the PEG-LMWH and PEG-HBP were characterized via both bulk rheology and laser tweezer microrheology. Interestingly, solutions of PEG-LMWH (2.5 wt \% in PBS) form hydrogels in the absence of PEG-ATIII or PEG-HIP, with storage moduli, determined via bulk rheological measurements, in excess of the loss moduli over frequencies of $0.1-100 \mathrm{~Hz}$. The addition of PEG-ATIII or PEG-HIP increases the moduli in direct proportion to the number of cross-links introduced. Characterization of the hydrogels via microrheology shows the gel microstructure is composed of polymer-rich fibrillar structures surrounded by polymer-depleted buffer. Potential applications of these hydrogels are discussed.
\end{abstract}

\section{Introduction}

Polymeric hydrogels have been widely applied in biomaterials investigations as drug delivery vehicles, cellular scaffolds, and space filling agents. These materials can be derived from naturally occurring polymers such as collagen, alginate, fibrin, and hyaluronic acid or from synthetic polymers such as poly(ethylene oxide), poly(vinyl alcohol), poly(acrylic acid), and poly( $N$-isopropyl acrylamide). ${ }^{1,2}$ The noncovalent assembly of hydrogels based on specific molecular recognition interactions has been increasingly investigated for the production of responsive, reversible, and injectable delivery systems, and although protein-protein interactions have been predominantly used for such assembly, ${ }^{3-6}$ polysaccharide-peptide interactions have also been recently reported. ${ }^{2}$ An important emerging theme in the design of hydrogels is also the incorporation of biological macromolecules to impart desired assembly, bioactivity, and responsiveness; accordingly, the use of specific noncovalent interactions between proteins and polysaccharides has also been applied for such immobilization. ${ }^{7,8}$ Given the many disparate functions that polysaccharides, and glycosaminoglycans in particular, serve

\footnotetext{
*To whom correspondence should be addressed. Tel.: (302) 831-0102. Fax: (302) 831-1048. E-mail: furst@ che.udel.edu.

$\dagger$ Department of Materials Science and Engineering.

Delaware Biotechnology Institute.

$\S$ Department of Chemical Engineering.
}

Supporting Information Available. Analysis of the purified solids via ${ }^{1} \mathrm{H}$ NMR. Binding curves for the interaction of the ATIII and HIP peptides with the LMWH-modified chip surface. This material is available free of charge via the Internet at http://pubs.acs.org. 
in vivo, such as mediating cell proliferation and migration, angiogenesis, wound healing, and inflammatory responses, the expanded use of specific polysaccharide-protein interactions for macromolecular assembly and biomacromolecule immobilization will provide versatile routes to multifunctional hydrogel materials. For example, the sulfated glycosaminoglycan heparin is known to bind to and mediate the activities of hundreds of proteins, such as growth factors, chemokines, viral coat proteins, lipoproteins, and enzymes (e.g., thrombin). ${ }^{9}$ The varied biological properties of heparin and related polysaccharides suggest important opportunities in broadening the use of specific protein-polysaccharide interactions in the design of bioactive hydrogel materials.

In addition to controlling assembly and biological properties, an understanding of the mechanical properties of hydrogels, and their origin, is crucial for enabling the production of improved materials and for understanding cell-materials interactions. Despite the importance of the local response of polymeric materials to the properties of the cellular microenvironment and the resulting mechanical cues to cells, ${ }^{10}$ the primary mode of characterization has been the measurement of bulk rheological and mechanical properties, as well as their bulk biological response in vitro and in vivo. Microrheology $11-13$ permits the characterization of the local mechanical and rheological properties that are coupled with cellular mechanics, cytoskeletal organization, and mechanotransduction, by measuring the motion of embedded colloidal particles to thermal, magnetic, or optical forces. These experiments are emerging as important methods in the design and production of new, multifunctional biomaterials.

We have reported separately ${ }^{14}$ the synthesis of a poly-(ethylene glycol)-LMWH (PEGLMWH) star copolymer and its utility in the assembly of growth-factor-releasing hydrogels via noncovalent peptide-heparin interactions (Figure 1). In this paper, we report the bulk rheological and microrheological characterization of the mechanical properties of these hydrogels. Our results support the general utility of peptide-polysaccharide interactions for hydrogel formation and demonstrate that the rheological properties of the hydrogels directly correlate with the composition of the hydrogel. The microrheological characterization of the networks demonstrates microscale heterogeneity that can be quantified and may prove to have an impact on the ultimate response of materials of this kind in biological applications.

\section{Experimental Procedures}

\section{Materials and Methods}

Hydroxy-terminated and thiol-terminated four-arm star poly(ethylene glycol)s $\left(M_{\mathrm{n}}=10300\right.$; $M_{\mathrm{W}}=11300$ and $M_{\mathrm{n}}=10000 ; M_{\mathrm{w}}=10800$, respectively) were purchased from Polymer Source (Dorval, QC, Canada). Low molecular weight heparin sodium salt (porcine intestinal mucosa, $\left.M_{\mathrm{r}}=3000\right)$ was obtained from Sigma (St. Louis, MO). For peptide synthesis and HPLC, the amino acids and HBTU (2-(1H-benzotriazole-1-yl)-1,1,3,3-tetramethyluronium hexafluorophosphate) were received from Protein Technologies, Inc. (Tucson, AZ). Rink amide MBHA (4-methylbenzhydrylamine) resin was purchased from EMD Biosciences (San Diego, CA). DMF and acetonitrile (HPLC grade) were obtained from Fisher (Fairlawn, NJ). All other chemicals were obtained from Sigma-Aldrich unless otherwise specified. All other reagents were used as received. ${ }^{1} \mathrm{H}$ NMR spectra were acquired on a Bruker DRX-400 NMR spectrometer. The samples were prepared by dissolving $10 \mathrm{mg}$ of sample in $1 \mathrm{~mL}$ of DMSO$d_{6}$ or deuterium oxide. The resulting solutions were placed in $5 \mathrm{~mm}$ NMR tubes and the spectra were recorded under standard quantitative conditions at ambient temperature. All spectra recorded in DMSO- $d_{6}$ and deuterium oxide were referenced to TMS and DSS, respectively, which were added to each NMR tube prior to analysis. Mass spectra were obtained on a Bruker Biflex III matrix assisted laser desorption ionization-time-of-flight (MALDI-TOF) mass spectrometer operated in the reflectron mode using delayed extraction. Spectra were acquired with a minimum of 50 laser shots per spectrum. Calibration was performed with Sequazyme 
Peptide Mass Standards Kit from Applied Biosystems. All MALDI analytes were dissolved in $50 \%$ acetonitrile in $0.3 \%$ TFA, containing matrix, cyano-4-hydroxycinnamic acid, at a concentration of $5 \mathrm{mg} / \mathrm{mL}$.

\section{Synthesis of the PEG-LMWH Conjugate (1)}

The synthesis of the PEG-LMWH conjugate utilized in the assembly of hydrogel networks was conducted as previously described. ${ }^{14}$ Briefly, low molecular weight heparin (LMWH) was $N$-deacetylated via treatment with hydrazine and reacted with 4-( $N$-maleimidomethyl) cyclohexanecarboxylic acid $N$-hydroxysuccinimide ester to introduce maleimide groups. SEC analysis of the $N$-deacetylated LMWH indicated that the hydrazinolysis reaction did not decrease the molecular weight of LMWH. The maleimide-functionalized LMWH was then reacted with thiol-terminated four-arm star PEG to yield $\mathbf{1}$. Assay of the reaction mixture via Ellman's reagent indicated complete reaction of the thiol groups. ${ }^{1} \mathrm{H}$ NMR analysis of the purified copolymer indicated a minimum functionalization of $73 \%$. Since this functionalization is sufficient for the formation of hydrogel networks (functionality > 2), $\mathbf{1}$ was employed in the assembly and characterization of noncovalently assembled hydrogels.

\section{Synthesis of the PEG-ATIII and PEG-HIP Conjugates (3)}

Peptide Synthesis-Two peptides were used in these investigations. The sequence CKRAFAKLAARLYRKA is derived from the well-studied heparin binding domain of antithrombin III (ATIII), ${ }^{15}$ whereas the peptide CRPKAKAKAKAKDQTK is derived from the heparin-binding domain of heparin interacting protein (HIP). ${ }^{16}$ The peptides were prepared via standard Fmoc solid-phase peptide chemistry with HBTU activation on a PS3 Automated Solid-Phase Peptide Synthesizer (Protein Technologies, Inc., Tucson, AZ). The peptides were cleaved from the resin with TFA/water/EDT/TIS (94:2.5:2.5:1) and precipitated in cold diethyl ether. Peptide purification was performed via reverse-phase chromatography on a Delta600 high-performance liquid chromatography (HPLC) instrument (Waters) equipped with a preparative Symmetry $300 \mathrm{C} 18$ column (Waters; $5 \mu \mathrm{m}$ particle size, $3.9 \times 150 \mathrm{~mm}$ ). The peptides were eluted from the column via the application of a linear gradient from 5\% to $70 \%$ solvent $\mathrm{B}$ over $49 \mathrm{~min}$ at $5 \mathrm{~mL} / \mathrm{min}$, where solvent $\mathrm{A}$ is $0.1 \% \mathrm{TFA}$ in water and solvent $\mathrm{B}$ is $0.1 \% \mathrm{TFA}$ in acetonitrile. The peptides were purified to a minimum of $99.5 \%$ purity as confirmed via HPLC. The mass of the purified peptides were confirmed via MALDI-TOF mass spectrometry (single peak observed), $m / z=1709.3\left[(\mathrm{M}+\mathrm{H})^{+}\right.$, calcd 1709.0] for the ATIII peptide, and $\mathrm{m} / \mathrm{z}$ $=1771.9\left[(\mathrm{M}+\mathrm{H})^{+}\right.$, calcd 1772.0] for the HIP peptide.

\section{Synthesis of Vinyl Sulfone Terminated Four-Arm Star PEG (2)}

Vinyl sulfone terminated four-arm star PEG was synthesized via protocols reported by Harris ${ }^{17}$ with some modifications, or via those reported by Lutolf and Hubbell. ${ }^{18}$ The slight modifications to these procedures and characterization of the polymers have been previously reported. ${ }^{14}$ Conversion of the hydroxy termini of four-arm star PEG to vinyl sulfone groups proceeded at yields similar to those previously reported by Harris or Lutolf (67-78\% and 90$98 \%$, respectively).

\section{General Procedure for Synthesis of PEG-ATIII (3a) and PEG-HIP (3b)}

The ATIII and HIP peptides carrying N-terminal cysteines were reacted via Michael addition with vinyl sulfone modified star PEG according to procedures reported by Lutolf and Hubbell. 18 To a $10 \mathrm{~mL}$ vial were added 2 and degassed PBS (pH 6.5, 0.10 M, 0.15 M NaCl). To this solution was added a degassed PBS solution ( $\mathrm{pH} 6.5,0.10 \mathrm{M}, 0.15 \mathrm{M} \mathrm{NaCl}$ ) of the ATIII or HIP peptide (2 equiv. to each vinyl sulfone functionality in 2 ). The reaction mixture was quickly sealed and stirred at room temperature for $16 \mathrm{~h}$. The crude product was purified via fast protein liquid chromatography (FPLC) with a Superdex 200 gel filtration column (Amersham, 
Piscataway, NJ) with isocratic elution, employing $0.2 \mathrm{M} \mathrm{NaCl}$ at a flow rate of $0.5 \mathrm{~mL} / \mathrm{min}$ as the eluting buffer. The fractions containing $\mathbf{3 a}$ or $\mathbf{3 b}$ were combined, dialyzed (SpectraPor membrane, MWCO $1000 \mathrm{Da}$ ) against water to remove $\mathrm{NaCl}$, and lyophilized to yield $\mathbf{3 a}$ or $\mathbf{3 b}$ as a white solid (typical yields $=70-86 \%$ ). Analysis of the purified solids via NMR (Supporting Information) indicated a minimum of 63 and 77\% functionalization of 3a and $\mathbf{3 b}$, respectively, regardless of the method of preparation of $\mathbf{2}$ employed in the synthesis. These peptide-functionalized copolymers were also sufficiently functionalized to be competent for cross-linking, and were therefore used in the assembly and characterization of the hydrogels.

\section{Heparin Binding Affinity}

Heparin Affinity Chromatography-Affinity chromatography was performed on an ÄKTA Explorer FPLC equipped with a HiTrap Heparin HP column (5 mL, 10 mg heparin/ $\mathrm{mL}$ gel, Amersham Biosciences Corp. Piscataway, NJ); peptides were detected spectrophotometrically at a wavelength of $214 \mathrm{~nm}$. The peptides were eluted from the column in phosphate buffer: Buffer A consisted of $10 \mathrm{mM}$ phosphate ( $\mathrm{pH}$ 7.4), and buffer B contained $10 \mathrm{mM}$ phosphate and $2 \mathrm{M} \mathrm{NaCl}(\mathrm{pH}$ 7.4). The column was equilibrated with buffer $\mathrm{A}$ for $2 \mathrm{~h}$ before the peptides were injected. Once each peptide was loaded onto the column, a gradient of $0-100 \%$ buffer B in buffer A was conducted over 20 column volumes. The measured conductivity at which the absorbance at $214 \mathrm{~nm}$ reached a maximum was used to determine the salt concentration required to elute the peptides.

\section{Surface Plasmon Resonance (SPR)}

Synthesis of Biotinylated LMWH-LMWH was fractionated and $N$-deacetylated via previously described methods. ${ }^{14}$ To a $10 \mathrm{~mL}$ vial were added the $N$-deacetylated LMWH (34 $\mathrm{mg}$ ), dry dowex 50WX4-200 ion-exchange resin (strongly acidic cation), and anhydrous DMF $(1 \mathrm{~mL})$. The reaction mixture was stirred at room temperature until complete dissolution of the LMWH was observed. The resin was filtered and to the filtrate were added a few drops of anhydrous triethylamine and a solution of $\mathrm{N}$-hydroxysuccinimido-biotin (2 equiv. to each free amine functionality in the $N$-deacetylated $\mathrm{LMWH})$ in $\mathrm{DMF}(0.5 \mathrm{~mL})$ and the reaction mixture was stirred at $60^{\circ} \mathrm{C}$ for $20 \mathrm{~h}$. The solvent was removed in vacuo to give a yellowish solid. This product was redissolved in PBS (pH 6.5) and dialyzed (SpectraPor membrane, MWCO 1000 Da) first against $1 \mathrm{M} \mathrm{NaCl}$ and finally water, and it was then lyophilized to afford a yellowish solid (23.3 mg, $64.8 \%$ overall yield).

Immobilization of Biotinylated LMWH—SPR sensorgrams were recorded at $25^{\circ} \mathrm{C}$ on a BiaCore 3000 instrument (Biacore Inc, Piscataway, NJ). A streptavidin sensor surface (SA sensor chip, Biacore Inc, Piscataway, NJ) was pretreated with three $40 \mu \mathrm{L}$ injections of $50 \mathrm{mM}$ $\mathrm{NaOH}$ in $1 \mathrm{M} \mathrm{NaCl}$, to remove any nonspecifically bound contaminants. The biotinylated LMWH $(100 \mu \mathrm{g} / \mathrm{mL})$ in HBS-EP running buffer (100 mM HEPES, $150 \mathrm{mM} \mathrm{NaCl}, 3 \mathrm{mM}$ EDTA, pH 7.4 containing $0.005 \%$ (v/v) P-20 surfactant) was injected $(2 \mu \mathrm{L})$ into a flow cell; a permanent increase of approximately $400 \mathrm{RU}$ was detected in the flow cell after injection of the biotinylated LMWH, indicating chip functionalization. An additional flow cell of the sensor chip was similarly treated with biotin alone as a control.

Kinetics Measurement of LMWH-Peptide Interactions via SPR-Surface plasmon resonance experiments were conducted according to standard protocols and experimental design principles. ${ }^{19-21}$ Injection of either the ATIII or HIP peptide $(120 \mu \mathrm{L}$ at a concentration range of $0.5-50 \mu \mathrm{M}$ in HBS-EP buffer) was made at a flow rate of $40 \mu \mathrm{L} / \mathrm{min}$ to ensure that there were no mass transport limitations. After peptide injection, the running buffer was then continuously passed over the sensor surface to monitor dissociation. After a 6 min dissociation phase, the sensor chip surface was regenerated for the next peptide sample injection with a 26 $\mu \mathrm{L}$ pulse of regenerating buffer ( $10 \mathrm{mM}$ glycine, $\mathrm{pH} 2.0$ ). Peptide-containing running buffer 
was also injected in the control flow cells, and the response was monitored as a function of time at $25^{\circ} \mathrm{C}$. Sensorgrams from the control cells were subtracted from the data for the LMWHmodified surfaces to correct for any refractive index changes from the buffer and any contribution of nonspecific interactions (which were insignificant). The dissociation and association rate constants, $k_{\mathrm{d}}$ and $k_{\mathrm{a}}$, were evaluated separately with the Biacore BIA Evaluation software, employing a 1:1 Langmuir interaction model, which provided an excellent fit to the experimental data. The dissociation rate constant, $k_{\mathrm{d}}$, was first obtained from the expression $\mathrm{d} R / \mathrm{d} t=-k_{\mathrm{d}} R$, where $R$ represents the sensor response. The observed association rate constant, $k_{\mathrm{S}}$, was calculated from the slope of the data during association, and $k_{\mathrm{a}}$ was calculated from the equation $k_{\mathrm{s}}=k_{\mathrm{d}}+k_{\mathrm{a}} C$, where $C$ represents the peptide concentration. The reported equilibrium dissociation constant, $K_{\mathrm{D}}$, was obtained from the ratio of $k_{\mathrm{d}} / k_{\mathrm{a}}$.

\section{Assembly of Networks, 4}

To assemble the hydrogel networks, a $10 \mathrm{wt} \%$ solution of $\mathbf{3 a}$ or $\mathbf{3 b}$ in PBS was added directly to a $2.5 \mathrm{wt} \%$ solution of $\mathbf{1}$ in PBS, to yield hydrogel networks $\mathbf{4 a}$ or $\mathbf{4 b}$. The solutions were mixed (by pipetting) in ligand mole ratios of 9:1, 8:2, and 6:4 (LMWH:HBP), which were calculated based on the molar ratio of PEG-LMWH and PEG-HBP in the mixture and the functionalization of each polymer. Changes in viscoelastic properties upon mixing were immediately apparent. After mixing, the polymer networks were either stored at $4{ }^{\circ} \mathrm{C}$ or were subsequently mixed with 10 parts of free LMWH, free ATIII peptide, or free HIP peptide, to elucidate the specificity of the interaction mediating hydrogel formation. The stored hydrogels were equilibrated to room temperature prior to rheological characterization (typically several minutes).

\section{Rheological Characterization}

Bulk rheological characterization was performed on single-component solutions of $\mathbf{1}$ and $\mathbf{3}$, in addition to $\mathbf{4}$ formed by mixtures of the two. Dynamic mechanical measurements of the hydrogel linear viscoelastic response were performed using a Rheometrics ARES 100 straincontrolled rheometer. All tests were conducted with a $50 \mathrm{~mm}$ diameter parallel-plate geometry at room temperature. The frequency dependence of the storage $G^{\prime}(\omega)$ and loss $G^{\prime \prime}(\omega)$ shear moduli was measured at different molar ratios of $\mathbf{1}$ and $\mathbf{3}$ in the linear regime. Samples were vortexed prior to loading in the rheometer. The sample was subjected to a pre-shear with 100 $\mathrm{s}^{-1}$ shear rate for $50 \mathrm{~s}$ and left at rest for $10 \mathrm{~min}$ prior to each measurement. After this time, the gel moduli showed no time dependence, ensuring that the initial conditions of each measurement were the same. The strain dependence of the response was measured to determine the range of linear viscoelasticity.

Laser tweezer microrheology was performed by measuring the response of dispersed colloidal polystyrene microspheres that are held by an oscillating optical trap (Figure 2). A single beam with transverse mode $\mathrm{TEM}_{00}$ from the $1064 \mathrm{~nm}$ line of a $4 \mathrm{~W}$ Nd:YAG laser was introduced into the side port of an inverted microscope (Zeiss Axiovert 200). The beam was expanded to overfill the back aperture of the objective (63X NA 1.2 Zeiss C-Apochromat), which generated the tight focus necessary for optical trapping. The trap position in the focal plane of the microscope was controlled using an acousto-optic deflector (AA Optoelectronics,

AA.DTS.XY-400) driven by computer software interface for a 16-bit digital acquisition board (National Instruments NI-6502E). The spatial resolution of the laser position was approximately $0.2 \mathrm{~nm} .{ }^{22}$ This enabled oscillation of the particles at small amplitudes, typically one-tenth of the particle diameter, at frequencies between 1 and $60 \mathrm{~Hz}$. Light scattered from the trapped particle using a co-aligned $10 \mathrm{~mW}$ HeNe laser (Melles-Griot) was collected by the condenser and imaged onto a quadrant photodiode, providing nanometer resolution of smallamplitude movements of the particle. ${ }^{23}$ The particle response to an oscillating optical trap is governed by the equation of motion 


$$
6 \pi a \eta \frac{\mathrm{d} x}{\mathrm{~d} t}+\left(\kappa_{\mathrm{e}}+\kappa_{\mathrm{t}}\right) x=\kappa_{\mathrm{t}} A \cos \omega t
$$

where $a$ is the particle radius, $A$ is the amplitude of the laser oscillation, $\kappa_{\mathrm{t}}$ is the laser trap stiffness, and $\eta$ and $\kappa_{\mathrm{e}}$ characterize the viscous and elastic forces exerted on the probe particle by the surrounding hydrogel. ${ }^{24,25}$ Note that $\kappa_{\mathrm{e}}$ is related to the shear modulus $\mu$ and Poisson ratio $v$ as

$$
\kappa_{\mathrm{e}}=24 \pi \mu a\left(\frac{1-v}{5-6 v}\right)
$$

The solution to eq 1 for the probe particle position is $x(t)=D(\omega) \cos [\omega t-\delta(\omega)]$, with the frequency-dependent amplitude

$$
D(\omega)=\frac{\kappa_{\mathrm{t}} A}{\left[\left(\kappa_{\mathrm{e}}+\kappa_{\mathrm{t}}\right)^{2}+(6 \pi a \eta \omega)^{2}\right]^{1 / 2}}
$$

and phase lag

$$
\tan \delta(\omega)=\frac{6 \pi a \eta \omega}{\kappa_{\mathrm{e}}+\kappa_{\mathrm{t}}}
$$

Both are computed using a lock-in amplifier (Stanford Research Systems SR830). The trap rigidity $\kappa_{\mathrm{t}}$ is found independently at each laser power by measuring the displacement of identical particles from the equilibrium position when subjected to a hydrodynamic drag force in water and water-glycerol solutions of increasing viscosity. Typical values of $\kappa_{\mathrm{t}}$ are $10-40$ $\mathrm{pN} / \mu \mathrm{m}$ for laser powers between 100 and $500 \mathrm{~mW}$.

Microrheology samples were prepared by first dispersing monodisperse latex microspheres ( $1.025 \mu \mathrm{m}$, Polysciences, Warrington, PA) in $\mathbf{1}$ and then mixing with 3. Samples were vortexed before adding small volumes $(<30 \mu \mathrm{L})$ to microscope slides, which were carefully sealed to prevent drying. Unless otherwise stated, the total polymer concentration was $2.5 \mathrm{wt} \%$ in all microrheology samples.

\section{Results}

\section{Synthesis of PEG Conjugates}

The synthesis of $\mathbf{1}$ and $\mathbf{3}$ has been described in a separate report. ${ }^{14}$ Briefly, maleimidefunctionalized LMWH was reacted with thiol-terminated four-arm star PEG to yield $\mathbf{1}$. Cysteine-terminated heparin-binding peptides were reacted with $\mathbf{2}$ to yield $\mathbf{3}$. Analysis of the reactive PEG termini over the course of the reactions used to form these bioconjugates suggests that the reactive end groups are mostly consumed prior to purification of the reaction mixture. Integration of the ${ }^{1} \mathrm{H}$ NMR spectra of the purified PEG conjugates indicated a minimum conversion of 73,63 , and $77 \%$, respectively, for $\mathbf{1}, \mathbf{3 a}$, and $\mathbf{3 b}$. The lack of complete conversion likely stems from the steric bulk of the LMWH (and peptides) during the reaction with the PEG chain ends. Nevertheless, each of the conjugates contains the required minimum number of functional groups to support network formation, and these conjugates were therefore used in experiments to assess their ability to form noncovalently assembled hydrogels on the basis of the interactions between the LMWH and the heparin-binding peptides (Figure 1). 


\section{Heparin Binding Affinity}

The binding affinity between the LMWH and the ATIII and HIP peptides was determined via heparin affinity chromatography and surface plasmon resonance investigations; results of these experiments are summarized in Table 1 . In the heparin chromatography experiment, each of the two peptides was loaded onto a heparin-sepharose column and then subjected to a gradient of increasing $\mathrm{NaCl}$ concentration; the concentration of $\mathrm{NaCl}$ required for peptide elution is related to the affinity of the peptide for heparin. The elution of the peptides from the heparinsepharose column required a salt concentration of $594 \pm 2 \mathrm{mM}$ for the ATIII peptide and 687 $\pm 1 \mathrm{mM}$ for the HIP peptide. Surface plasmon resonance experiments were also employed to estimate the binding affinities of the peptides for the LMWH employed in hydrogel assembly. The binding of the peptides to a LMWH-modified SA chip surface, at various peptide concentrations, was monitored under conditions described in the Experimental Section. Despite reports of nonspecific binding of heparin-binding proteins to SA chips and chip instability 26 no such nonspecific binding or instability was observed for the heparin-binding peptides with the SA surface. The binding curves for the interaction of the ATIII and HIP peptides with the LMWH-modified chip surface are shown in the Supporting Information. Analysis of the association and dissociation regions of the binding curves demonstrated that the association of the ATIII peptide with LMWH proceeded with a rate constant of $1.56 \pm 0.06$ $\times 10^{2} \mathrm{M}^{-1} \mathrm{~s}^{-1}$, whereas the dissociation proceeded with a rate constant of $2.0 \pm 0.3 \times 10^{-3}$ $\mathrm{s}^{-1}$, yielding a $K_{\mathrm{D}}$ of approximately $12.9 \pm 1.3 \mu \mathrm{M}$. Similar analysis for the HIP peptide indicated that the association proceeded more quickly, with a rate constant of $1.10 \pm 0.08 \times$ $10^{3} \mathrm{M}^{-1} \mathrm{~s}^{-1}$, whereas the dissociation proceeded at a similar rate, with a rate constant of 4.64 $\pm 0.02 \times 10^{-3} \mathrm{~s}^{-1}$, yielding a $K_{\mathrm{D}}$ of $4.2 \pm 0.3 \mu \mathrm{M}$. These results demonstrate that the LMWH is competent for binding to both peptides, with slightly different affinities; formation of $\mathbf{4}$ via noncovalent interactions between $\mathbf{1}$ and $\mathbf{3}$ was therefore investigated.

\section{Hydrogel Formation}

Solutions of the two polymer conjugates, $\mathbf{1}$ and $\mathbf{3}$ (either ATIII or HIP), in PBS were mixed at a final concentration of $2.5 \mathrm{wt} \%$, at ligand mole ratios of 9:1, 8:2, and 6:4 (LMWH:HBP) to give 4. The formation of self-supporting gels was immediately apparent upon mixing. In the case of $\mathbf{4 a}$, each of these mixtures resulted in a single-phase hydrogel. In the case of $\mathbf{4 b}$, however, the $2.5 \mathrm{wt} \%$ mixtures excluded significant volumes of buffer at all relative compositions investigated. Upon quantitative removal of the buffer via pipetting, the hydrogel phase was estimated to contain approximately $7 \mathrm{wt} \%$ polymer in each case. The syneresed fluid was analyzed via size exclusion chromatography (SEC), which indicated that there was no detectable amount of polymer present in the liquid phase. The hydrogel phases of $\mathbf{4}$ were characterized via bulk rheology and microrheology. 4 could be resolubilized upon addition of either free LMWH or appropriate peptide (ATIII or HIP), suggesting that the interactions of LMWH with the peptide are mediating hydrogel formation in these systems.

\section{Rheological Characterization}

As controls prior the hydrogel characterization experiments, the rheological behavior of each of the components was determined separately. Microrheological measurements of hydroxyterminated four-arm star PEG and LMWH solutions are shown in Figure 3 for weight fractions up to $10 \%$; the solutions exhibited viscosities between 1 and $5 \mathrm{mPa}$ s, which is given by eq 4 when the slope of $\tan \delta(\omega)$ is plotted versus frequency. For star PEG solutions, the viscosities are within the range of experimental error of values obtained using a falling ball rheometer. Similar to star PEG and LMWH solutions, the viscosities of $10 \mathrm{wt} \%$ of $\mathbf{3 a}$ and $\mathbf{3 b}$ are 3.4 and $4.4 \mathrm{mPa}$ s, respectively, slightly below the viscosity of $10 \mathrm{wt} \% \mathrm{LMWH}$ and above the viscosity of $10 \mathrm{wt} \%$ star PEG. 
In contrast to the viscous response of the solutions of star PEG, LMWH, or $\mathbf{3 a}$ and $\mathbf{3 b}$, the bulk rheology of $2.5 \mathrm{wt} \%$ of $\mathbf{1}$ in PBS exhibits a substantial elastic response, shown in Figure 4A. The storage modulus increases from $G^{\prime}(\omega) \approx 16 \mathrm{~Pa}$ at $0.1 \mathrm{~Hz}$ to $27 \mathrm{~Pa}$ at $100 \mathrm{~Hz}$, and is greater than $G^{\prime \prime}(\omega)$ by approximately an order of magnitude over the entire range of frequencies. $G^{\prime \prime}$ $(\omega)$ increases slightly at higher frequencies, with a shallow minimum at $\omega \approx 0.5 \mathrm{~Hz}$. At $7.1 \mathrm{wt}$ $\%$ of $1, G^{\prime}(\omega)$ increases to $80-100 \mathrm{~Pa}$, about a factor of 4 over the $2.5 \mathrm{wt} \%$ solution of 1 . The loss modulus increases by a similar factor. Strain sweeps conducted on $2.5 \mathrm{wt} \%$ of $\mathbf{1}$ (Figure 4B inset) show the presence of a yield stress (Figure 4B), indicated by the maximum when the in-phase stress component $\tau^{\prime}=G^{\prime} \gamma_{0}$ is plotted against the strain amplitude. ${ }^{27}$ The yield stress is approximately $2.8 \mathrm{~Pa}$ at $23 \%$ strain.

\section{Microrheology of 1}

Microrheological measurements demonstrate a considerable degree of microstructure in $\mathbf{1}$. In Figure 5, several representative laser tweezer microrheology measurements from a $2.5 \mathrm{wt} \%$ of $\mathbf{1}$ are presented. The response depends strongly on the location of the probe particle, indicated by variations in the slope of $\tan \delta(\omega)$ for different locations in the network. Still images captured from video microscopy during the experiments show filamentous structures with widths on the order of the probe size, lengths that are tens of microns long, and large regions, several to tens of microns, between filaments. As the probe particle is brought into closer proximity to the microstructure, $\tan \delta(\omega)$ increases due to hydrodynamic resistance caused by the filament. The apparent viscosities for the curves in Figure 5 are $1.1 \pm 0.1 \mathrm{mPa} \mathrm{s}, 3.9 \pm 0.1 \mathrm{mPa}$ s, and $4.8 \pm 0.2 \mathrm{mPa}$ s. Interestingly, the lowest values occur in the interstitial regions, and give viscosities similar to that of water, implying that these regions are devoid of significant amounts of polymer.

\section{Bulk Rheology of 4}

The addition of $\mathbf{3}$ significantly increases the magnitude of $G^{\prime}(\omega)$ and $G^{\prime \prime}(\omega)$. For $\mathbf{4 a}$, this increase is monotonic with increasing molar ratio of the peptide component. As shown in Figure 6A, the average $G^{\prime}(\omega)$ increases to approximately 30,70 , and $150 \mathrm{~Pa}$ for molar ratios of LMWH to ATIII of 9:1, 8:2, and 6:4, respectively. Relative increases in $G^{\prime \prime}(\omega)$ are also observed. The addition of 3a increases the magnitude of the yield stress and the corresponding strain, which are shown in Figure 6B for 9:1 and 8:2 molar ratio mixtures and for $\mathbf{1}$. The yield stress is approximately $10 \mathrm{~Pa}$ at $27 \%$ strain for the 9:1 sample, and approximately $24 \mathrm{~Pa}$ at $32 \%$ strain for the $8: 2$ sample.

Similar to $\mathbf{4 a}$, the addition of $\mathbf{3 b}$ increases the viscoelastic modulus of $\mathbf{4 b}$ as shown in Figure 7. However, samples formed with $\mathbf{3 b}$ exhibit syneresis and an expulsion of buffer after gentle mixing for $30 \mathrm{~s}$. The supernatant solvent is removed and analyzed via SEC. Since the syneresed buffer shows no significant concentration of polymer, the final weight fraction of $\mathbf{1}$ is estimated to be approximately $7 \mathrm{wt} \%$. As discussed above, the higher weight fraction of polymer results in correspondingly higher storage moduli for samples formed with $\mathbf{4 b}$ versus $\mathbf{4 a}$. As $\mathbf{3 b}$ is introduced, $G^{\prime}(\omega=0.1 \mathrm{~Hz})$ initially exhibits a monotonic increase to 125 and $207 \mathrm{~Pa}$ for 9:1 and 8:2 molar ratios, respectively, again, with a corresponding increase in the loss moduli. Interestingly, at a 6:4 molar ratio of LMWH to HIP, the storage modulus increases only moderately from the 8:2 sample, to approximately $226 \mathrm{~Pa}$ at $0.1 \mathrm{~Hz}$. The effects on storage modulus of adding $\mathbf{3 a}$ and $\mathbf{3 b}$ to $\mathbf{1}$ are summarized in Figure 8 for $G^{\prime}(\omega=0.1 \mathrm{~Hz})$ plotted as a function of the ratio of HBP to LMWH in the sample. Although the absolute magnitudes of $G$ ' $(\omega=0.1 \mathrm{~Hz})$ upon addition of increasing amounts of $\mathbf{3 a}$ and $\mathbf{3} \mathbf{b}$ are different due to the difference in polymer concentration caused by syneresis (cf. inset of Figure 8), the curves collapse onto one another when normalized by the initial elastic modulus of 1 . Figure 8 clearly demonstrates the similar linear increase of the storage modulus of $\mathbf{4 a}$ and $\mathbf{4 b}$ with the addition of $\mathbf{3 a}$ or $\mathbf{3 b}$, with $\mathbf{4 b}$ exhibiting a plateau at higher molar ratios of HIP to LMWH. 


\section{Discussion}

The bioconjugates, $\mathbf{1}$ and $\mathbf{3}$, were synthesized to take advantage of biologically relevant polysaccharide-peptide interactions in hydrogel assembly. Heparin was chosen as the polysaccharide in these investigations due to its chemical and biological versatility. Lowmolecular weight heparin was utilized in order to minimize the potential for chemical crosslinking during the synthesis of $\mathbf{1}$ as well as to minimize the potential for intramolecular interactions upon mixing of $\mathbf{1}$ and $\mathbf{3} .{ }^{14}$ Modification of the free amino groups of LMWH, with maleimide, was employed here to permit facile attachment of the LMWH to thiol-terminated four-arm star PEG. Assessments of LMWH-peptide binding affinity via SPR (see below) indicated that the modified LMWH remained competent for peptide binding and that therefore the conjugation methods employed here should prove useful for the synthesis of polymers capable of noncovalent assembly.

The heparin-binding regions of antithrombin III (ATIII, CK $\beta$ AFAKLAARLYRKA) and of the heparin interacting protein (HIP, CRPKAKAKAKAKDQTK) were employed in the synthesis of 3. These positively charged peptides are of similar length (15 and 16 amino acids long, respectively) 15,28 and bind to a heparin affinity column with slightly different affinities that are consistent with those previously reported for similar peptides. ${ }^{2}$ Since the heparin affinity chromatography assesses the affinity of the peptides for high molecular weight heparin, SPR characterization of the affinity of the peptides for LMWH was also monitored. These experiments permit comparison of the affinities of the peptides for LMWH immobilized via its free amines, which is directly correlated to the binding events that mediate hydrogel assembly. The results of the SPR experiments demonstrate that both peptides bind LMWH with micromolar affinity. The fact that these peptides would bind LMWH is consistent with the fact that both peptides are reported to bind to pentasaccharide sequences in heparin 29,30 and that the LMWH employed in these experiments ranges in length from a deca to a didodecasaccharide. ${ }^{14}$ The $K_{\mathrm{D}}$ values determined in the SPR experiments for the binding of the ATIII peptide with LMWH (Table 1) are consistent with values previously reported for the binding of ATIII to LMWH, ${ }^{31}$ although they are significantly greater than the value of $51 \mathrm{nM}$ determined calorimetrically for the binding of ATIII to high molecular weight heparin. ${ }^{15}$ The $K_{\mathrm{D}}$ values determined for the binding of HIP to LMWH are also greater than the $K_{\mathrm{D}}$ value of $254 \mathrm{nM}$ determined via solid-phase assays for the binding of the HIP peptide to high molecular weight heparin. ${ }^{28}$ The higher $K_{\mathrm{D}}$ values determined in the experiments here are not unexpected, given that there are likely additional longer-range interactions that stabilize the interaction of the peptides with high molecular weight heparin. Nevertheless, the SPR data are consistent with the heparin affinity chromatography results, indicating that the ATIII peptide exhibits a similar but slightly lower affinity for LMWH than the HIP peptide. Furthermore, these experiments demonstrate that both peptides bind to LMWH and should therefore be useful for mediating assembly and modulating rheological behavior of hydrogels.

Indeed, $\mathbf{1}$ and $\mathbf{4}$ exhibit the viscoelastic properties of gels, as defined by their rheological characteristics. ${ }^{32}$ First, $G^{\prime}(\omega)$ exhibits a pronounced plateau extending to frequencies of tens to hundreds of reciprocal seconds. Second, $G^{\prime \prime}(\omega)$ is significantly smaller in magnitude than the storage modulus over all measured frequencies. Based on the affinity between LMWH and the ATIII and HIP peptides, we expect physical gels to form in mixtures of $\mathbf{1}$ and $\mathbf{3}$. However, in such a case, the gels are expected to exhibit a relaxation time associated with the dissociation rate of the LMWH-peptide interaction. For instance, Wachsstock and co-workers demonstrated that the frequency dependence and magnitude of the viscoelastic modulus in cross-linked semiflexible filamentous actin (F-actin) solutions depends on the cross-linker dissociation time scale. ${ }^{33,34}$ Similarly, polymer solutions that exhibit transient interactions, such as telechelics, exhibit a single rheological relaxation time governed by the lifetime of the interaction. ${ }^{35,36}$ Instead, it is clear that the baseline elastic response observed in $\mathbf{4}$ stems from 
the viscoelastic properties of $\mathbf{1}$. Furthermore, it is surprising that $\mathbf{1}$ exhibits gel behavior, since the individual components (star PEG and LMWH solutions) exhibit purely viscous properties. Clearly, the large elastic modulus of $\mathbf{1}$ is a result of the underlying filamentous microstructure.

The microstructure of $\mathbf{1}$ and the resulting viscoelastic properties most likely result from physical interactions between conjugated LMWH groups in $\mathbf{1}$. There is no indication upon SEC purification that there are any significantly higher molecular weight fractions present in the samples used for the rheological studies, which makes it unlikely that the gel-like properties of 1 are caused by a percolated network formed via unanticipated covalent cross-linking. Furthermore, at the concentrations of these experiments, a noninteracting, higher molecular weight polymer would be below the percolation threshold and would exhibit relaxation to viscous-like properties at low frequencies, in contrast to the measured response of $1 .^{37}$ The observation of fibrillar microstructure and significant storage modulus at low frequencies therefore supports the supposition that a physical gel forms through LMWH-mediated interactions in the solutions of $\mathbf{1}$. Association of the highly anionic LMWH termini in PBS solution may be expected based on extensive literature describing the association of likecharged polyelectrolytes in dilute salt solutions, $16,38-40$ in which association is thought to be mediated by charge fluctuations along the length of the polyelectrolyte that result from condensation of counterions on the polyelectrolyte chain. The reported association of highly negatively charged polyelectrolytes such as DNA and polystyrenesulfonate at similar polymer molecular weights ( $\sim 5000 \mathrm{Da})$, polymer concentrations ( $25 \mathrm{~g} / \mathrm{L})$, and salt concentrations (150 $\mathrm{mM})$ as those reported here suggests the possibility of this hypothesis. Limited reports of aggregation between heparin molecules, as assessed via size exclusion chromatography and light scattering methods, ${ }^{41}$ also support this hypothesis. The reason that the observed microstructure forms is still an open question, but entanglements between filaments would give rise to significant viscoelastic response. More detailed investigations of the association of the chemically modified LMWH reported here are underway to better determine the exact mechanisms behind the formation of the elastic network in $\mathbf{1}$.

From the combination of the rheological characterization of $\mathbf{4}$ and biochemical characterization of the relevant non-covalent interactions, it is clear that an initial level of viscoelastic behavior is introduced into these gels from the properties of $\mathbf{1}$ alone. It is also apparent that the addition of $\mathbf{3}$ provides further cross-linking that results in a significant increase in the elastic modulus of 4 (Figures 5 and 6), which is consistent with the noncovalent assembly between LMWH and HBP expected based on affinity chromatography and SPR results. In the inset of Figure 8, the elastic moduli at $\omega=0.1 \mathrm{~Hz}$ for $\mathbf{4 a}$ and $\mathbf{4 b}$ are plotted versus the molar ratio of HBP and LMWH, corrected for the fraction of derivatization for each PEG-conjugated species. When rescaled to the modulus of $\mathbf{1}$ at $2.5 \mathrm{wt} \%$, which corrects for the higher concentration of $\mathbf{1}$ in the syneresed $\mathbf{4 b}$, both curves collapse onto a master curve at low cross-linking ratios (Figure 8 ). These data show that the secondary cross-linking correlates directly to the molar amount of the HBP added to the solution, Figure 8, confirming that the binding of HBP to sites on LMWH in $\mathbf{1}$ is the source of the additional cross-linking 32 and that both peptides are similarly competent for cross-linking despite small differences in their measured heparin binding affinity and kinetics. Consistent with these results, the addition of either HBP or LMWH to $\mathbf{4}$ results in dissolution of the gel. Interestingly, the plateau in the modulus with increasing HIP concentration may suggest that the number of HIP peptide binding sites in the LMWH has been saturated. Although the HIP and ATIII peptides are thought to bind to a similar pentasaccharide in heparin, ${ }^{29}$ it is possible that subtle differences in the number and type of binding regions (on LMWH) for these two molecules are being probed in the rheology experiments.

PEG-peptide system mixed with high molecular weight heparin has been previously reported to produce viscoelastic gels. ${ }^{2}$ The storage modulus exceeded the loss modulus at frequencies 
exceeding $4 \mathrm{~Hz},{ }^{2}$ suggesting that the heparin/peptide interactions created higher molecular weight macromolecular species that could form entanglements and that demonstrate frequency-dependent viscoelastic properties characteristic of high molecular weight polymer solutions. In contrast, solutions of $\mathbf{1}$ reported here demonstrate elastic moduli that exceed the loss moduli at all frequencies measured, likely owing to the fibrillar network formed by $\mathbf{1}$. Similar to the previous report, the moduli can be tuned via additional cross-linking upon addition of PEG-HBP. The measured elastic moduli of $\mathbf{1}$ and $\mathbf{4}$ (100-200 Pa) are similar to those reported for other noncovalently associated polymeric hydrogels at similarly low weight percentages, such as leucine-zipper associated hydrogels ${ }^{3}$ and gelatin/hyaluronic acid hydrogels. ${ }^{42}$ Rapidly and noncovalently assembled materials that have moduli in this range have been proposed for use in wound healing and soft tissue engineering applications, in which cell encapsulation and controlled and responsive reagent delivery are of interest. The potential of hydrogels such as $\mathbf{1}$ and $\mathbf{4}$ in such applications is also suggested by the fact that the hydrogels are competent for binding to basic fibroblast growth factor and permit its controlled release over a period of weeks, ${ }^{14}$ with release correlated to the erosion properties of the network. The release of growth factors from these hydrogels is consistent with that reported for other polysaccharide-derivatized hydrogels $8,43-45$ but with the advantage that assembly and erosion are mediated by specific polysaccharide/peptide interactions. Taken altogether, these results demonstrate that PEG-LMWH hydrogels with varying elastic properties can be formed via interactions of PEG-LMWH and multiple heparin-binding peptides and that these interactions are useful for controlling both the rheological properties and biological activity of the hydrogels. Furthermore, the hydrogels could also be tailored with controlled properties and multiple activities via the inclusion of multiple heparin-binding peptides and proteins of varying affinities. The production of such multifunctional materials and manipulation of their rheological properties are under investigation.

\section{Conclusions}

These studies demonstrate that the PEG-LMWH conjugate is capable of forming hydrogels at low concentrations ( $2.5 \mathrm{wt} \%)$; microrheological characterization of these networks has revealed that a microfibrillar structure supports the elastic properties of the network. It is likely that this microfibrillar structure and resulting rheological properties arise from noncovalent polyelectrolyte-mediated interactions between LMWH on the termini of the PEG-LMWH conjugate, as suggested by the measured yield stress of these materials. Bulk rheological characterization of the PEG-LMWH and mixtures of PEG-LMWH and PEG-HBP indicate that the elastic moduli of these materials can be increased in direct proportion to the number of HBP termini added to the PEG-LMWH. Although differences in the LMWH binding affinity and kinetics are not probed in the rheology experiments described here, the measured differences in affinity via chromatography and SPR likely account for differences in the phase separation behavior of PEG-LMWH/PEG-HIP mixtures versus PEG-LMWH/PEG-ATIII mixtures. The higher affinity of the LMWH-HIP interaction appears to result in phase separation and syneresis that is not observed in the gels that contain PEG-ATIII. These results suggest the general utility of LMWH-HBP interactions as a strategy to assemble hydrogels, and our preceding report indicates the potential utility of these hydrogels for the binding and controlled release of heparin-binding growth factors. The ability to tailor LMWH-HBP interactions to control hydrogel assembly and properties would represent a versatile strategy for the production of noncovalent, biologically responsive materials. Elucidation of the detailed mechanisms for hydrogel formation in PEG-LMWH, as well as of differences in hydrogel assembly, rheological properties, and growth factor delivery as a function of higher-affinity interactions between LMWH and HBP, will be the subject of future reports. 


\section{Acknowledgements}

This work has been supported in part by grants from the National Institutes of Health (5-P20-RR15588; 1-R01EB003172-01), the National Science Foundation (CTS-0238689), and the Arnold and Mabel Beckman Foundation. Alyssa Panitch, Brandon Seal, and Vivek Prabhu are thanked for helpful discussions.

\section{References and Notes}

1. Drury JL, Mooney DJ. Biomaterials 2003;24:4337-4351. [PubMed: 12922147]

2. Seal BL, Panitch A. Biomacromolecules 2003;4:1572-1582. [PubMed: 14606882]

3. Petka WA, Hardin JL, McGrath KP, Wirtz D, Tirrell DA. Science 1998;281:389-392. [PubMed: 9665877]

4. Miyata T, Asami N, Uragami T. Nature 1999;399:766-769. [PubMed: 10391240]

5. Wang C, Stewart RJ, Kopecek J. Nature 1999;397:417-420. [PubMed: 9989405]

6. Wang C, Kopecek J, Stewart RJ. Biomacromolecules 2001;2:912-920. [PubMed: 11710049]

7. Sakiyama-Elbert SE, Hubbell JA. J Controlled Release 2000;65:389-402.

8. Wissink MJB, Beernink R, Pieper JS, Poot AA, Engbers GHM, Beugeling T, van Aken WG, Feijen J. Biomaterials 2001;22:2291-2299. [PubMed: 11456069]

9. Capila I, Linhardt RJ. Angew Chem, Int Ed 2002;41:390-412.

10. Parker KK, Brock AL, Brangwynne C, Mannix RJ, Wang N, Ostuni E, Geisse NA, Adams JC, Whitesides GM, Ingber DE. FASEB J 2002;16

11. Ziemann F, Radler J, Sackmann E. Biophys J 1994;66:2210-2216. [PubMed: 8075354]

12. Mason TG, Weitz DA. Phys Rev Lett 1995;74:1250-1253. [PubMed: 10058972]

13. Schnurr B, Gittes F, MacKintosh FC, Schmidt CF. Macromolecules 1997;30:7781-7792.

14. Yamaguchi N, Kiick KL. Biomacromolecules 2005;6:1921-1930. [PubMed: 16004429]

15. Tyler-Cross R, Sobel M, McAdory L, Harris R. Arch Biochem Biophys 1996;334:206-213. [PubMed: 8900394]

16. Ha BY, Liu AJ. Phys Rev Lett 1997;79:1289-1292.

17. Morpurgo M, Veronese FM, Kachensky D, Harris JM. Bioconjugate Chem 1996;7:363-368.

18. Lutolf MP, Hubbell JA. Biomacromolecules 2003;4:713-722. [PubMed: 12741789]

19. Karlsson R, Falt A. J Immunol Methods 1997;200:121-133. [PubMed: 9005951]

20. Rich RL, Myszka DG. Curr Opin Biotech 2000;11:54-61. [PubMed: 10679342]

21. Osmond RIW, Kett WC, Skett SE, Coombe DR. Anal Biochem 2002;310:199-207. [PubMed: 12423639]

22. Pantina JP, Furst EM. Langmuir 2004;20:3940-3946. [PubMed: 15969383]

23. Gittes F, Schmidt CF. Opt Lett 1998;23:7-9. [PubMed: 18084394]

24. Valentine MT, Dewalt LE, OuYang HD. J Phys: Condens Matter 1996;8:9477-9482.

25. Ou-Yang, HD. Colloid-Polymer Interactions: From Fundamentals to Practice. Wiley; New York: 1999. p. 382-405.

26. Zhang F, Fath M, Marks R, Linhardt RJ. Anal Biochem 2002;304:271-273. [PubMed: 12009707]

27. Yang MC, Scriven LE, Macosko CW. J Rheol 1986;30:1015-1029.

28. Liu S, Julian J, Carson DD. J Biol Chem 1998;273:9718-9726. [PubMed: 9545307]

29. Liu S, Zhou F, Hook M, Carson DD. Proc Natl Acad Sci USA 1997;94:1739-1744. [PubMed: 9050848]

30. Lindahl U, Backstrom G, Thunberg L. J Biol Chem 1983;258:9826-9830. [PubMed: 6885772]

31. Watton J, Longstaff C, Lane DA, Barrowcliffe TW. Biochemistry 1993;32:7286-7293. [PubMed: 8343518]

32. Ferry, JD. Viscoelastic properties of polymers. Wiley; New York: 1980.

33. Wachsstock DH, Schwarz WH, Pollard TD. Biophys J 1993;65:205-214. [PubMed: 8369430]

34. Wachsstock DH, Schwarz WH, Pollard TD. Biophys J 1994;66:801-809. [PubMed: 8011912]

35. Tanaka F, Edwards SF. J Non-Newtonian Fluid Mech 1992;43:247-271. 
36. Tanaka F, Edwards SF. J Non-Newtonian Fluid Mech 1992;43:273-288.

37. Winter, HH.; Mours, M. Neutron Spin-Echo Spectroscopy Viscoelasticity Rheology. 134. Springer; New York: 1997. p. 165-234.

38. Wissenberg P, Odijk T, Cirkel P, Mandel M. Macromolecules 1995;28:2315-2328.

39. Sedlak M, Amis EJ. J Chem Phys 1992;96:826-834.

40. Matsuoka H, Ogura Y, Yamaoka H. J Chem Phys 1998;109:6125-6132.

41. Gaigalas AK, Hubbard JB, Lesage R, Atha D. J Pharm Sci 1995;84:355-359. [PubMed: 7616377]

42. Crescenzi V, Francescangeli A, Taglienti A. Biomacromolecules 2002;3:1384-1391. [PubMed: 12425680]

43. Liu L-S, -K NC, Thompson AY, Poser JW, Spiro RC. J Biomed Mater Res 2002;62:128-135. [PubMed: 12124794]

44. Chinen N, Tanihara M, Nakagawa M, Shinozaki K, Yamamoto E, Mizushima Y, Suzuki Y. J Biomed Mater Res A 2003;67A:61-68. [PubMed: 14517862]

45. Lee KY, Peters MC, Mooney DJ. J Controlled Release 2003;87:49-56. 


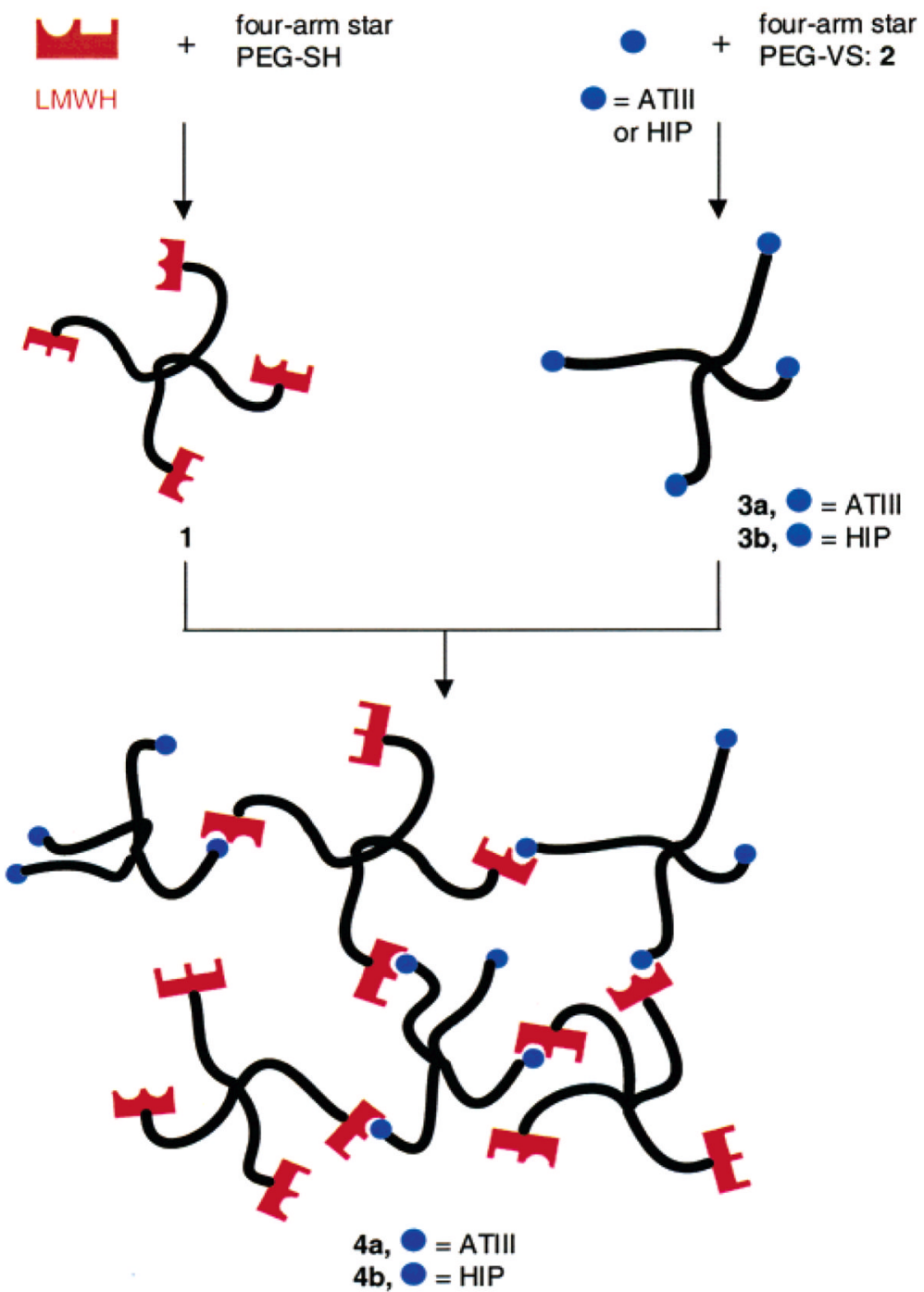

Figure 1.

Schematic of the assembly of hydrogel networks, 4, via the interaction of PEG-LMWH, $\mathbf{1}$, with PEG-HBP star copolymers, 3 . Potential HIP and ATIII peptide binding domains in LMWH are indicated by half circles. Rectangles denote binding sites on the LMWH that are specific for heparin binding peptides and/or proteins other than HIP and ATIII (e.g., for growth factors and other proteins). 


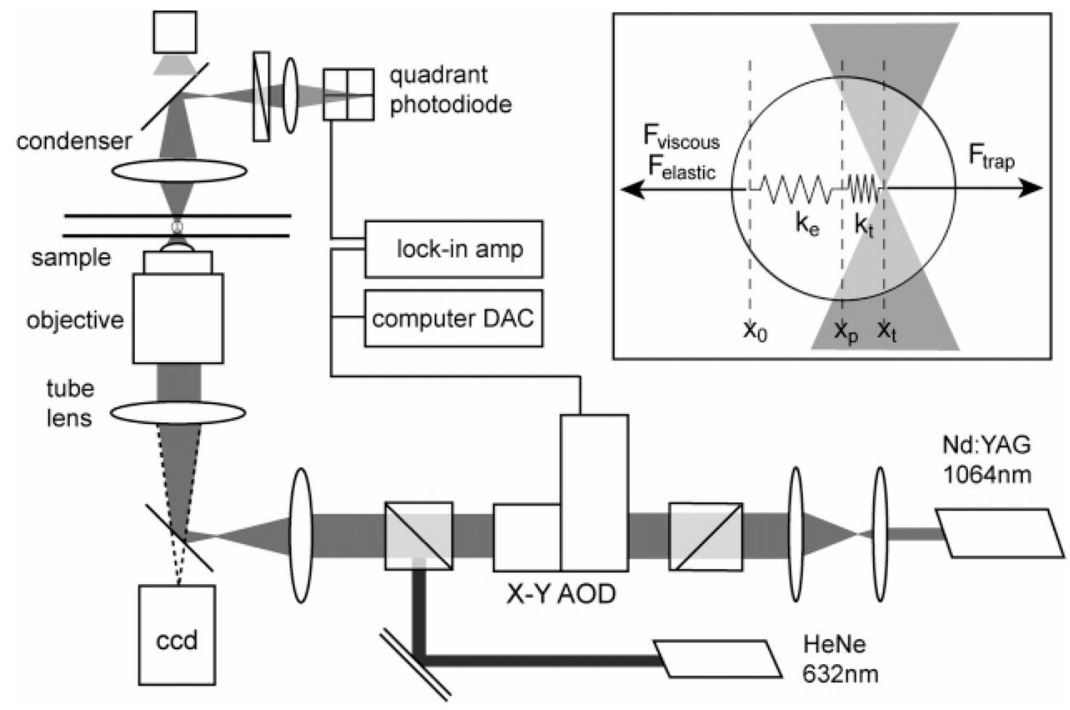

Figure 2.

Laser tweezer microrheology apparatus. The inset illustrates the force balance on a trapped microsphere, which includes, the Hookean-like force of the oscillating laser tweezer and the local viscous and elastic forces. 


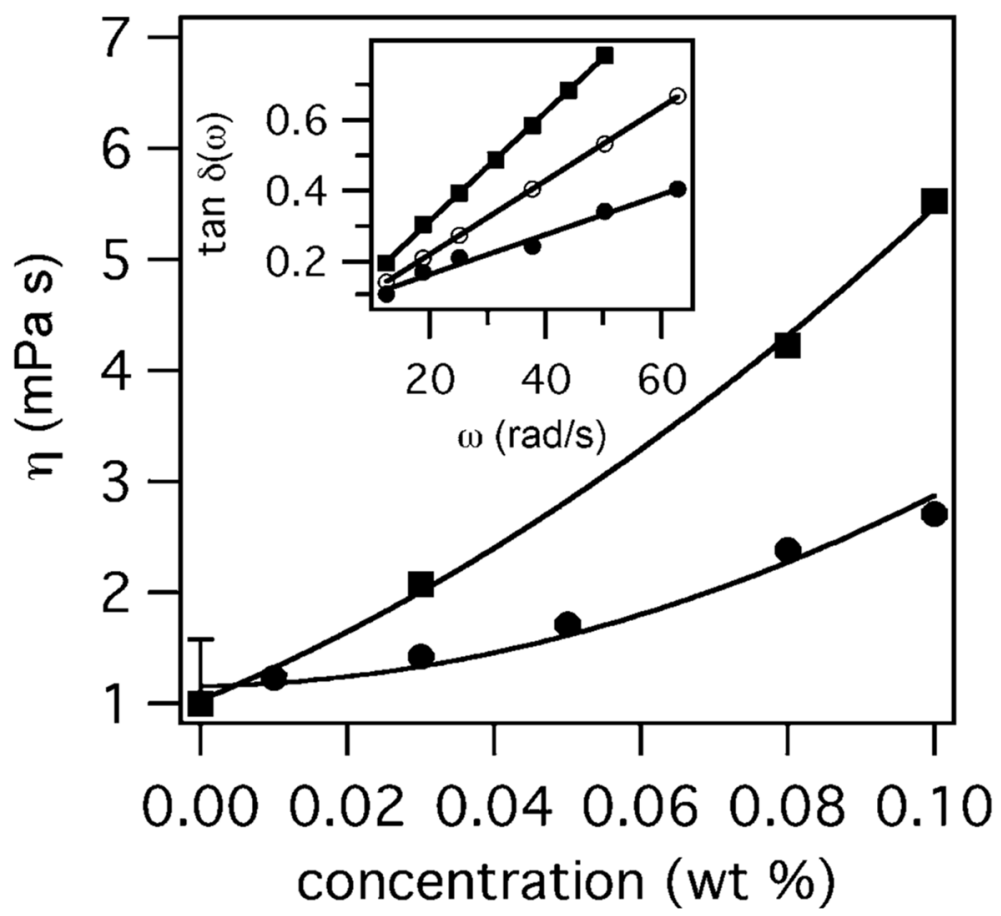

Figure 3.

Single-component solutions of star PEG (circles) and LMWH (squares) are viscous over the range of concentrations investigated in this study. The inset demonstrates the increasing slope and linear fits of $\tan \delta(\omega)$ versus frequency for star PEG solutions of 0 (closed circles), 3 (open circles) and $10 \mathrm{wt} \%$ (closed squares). 

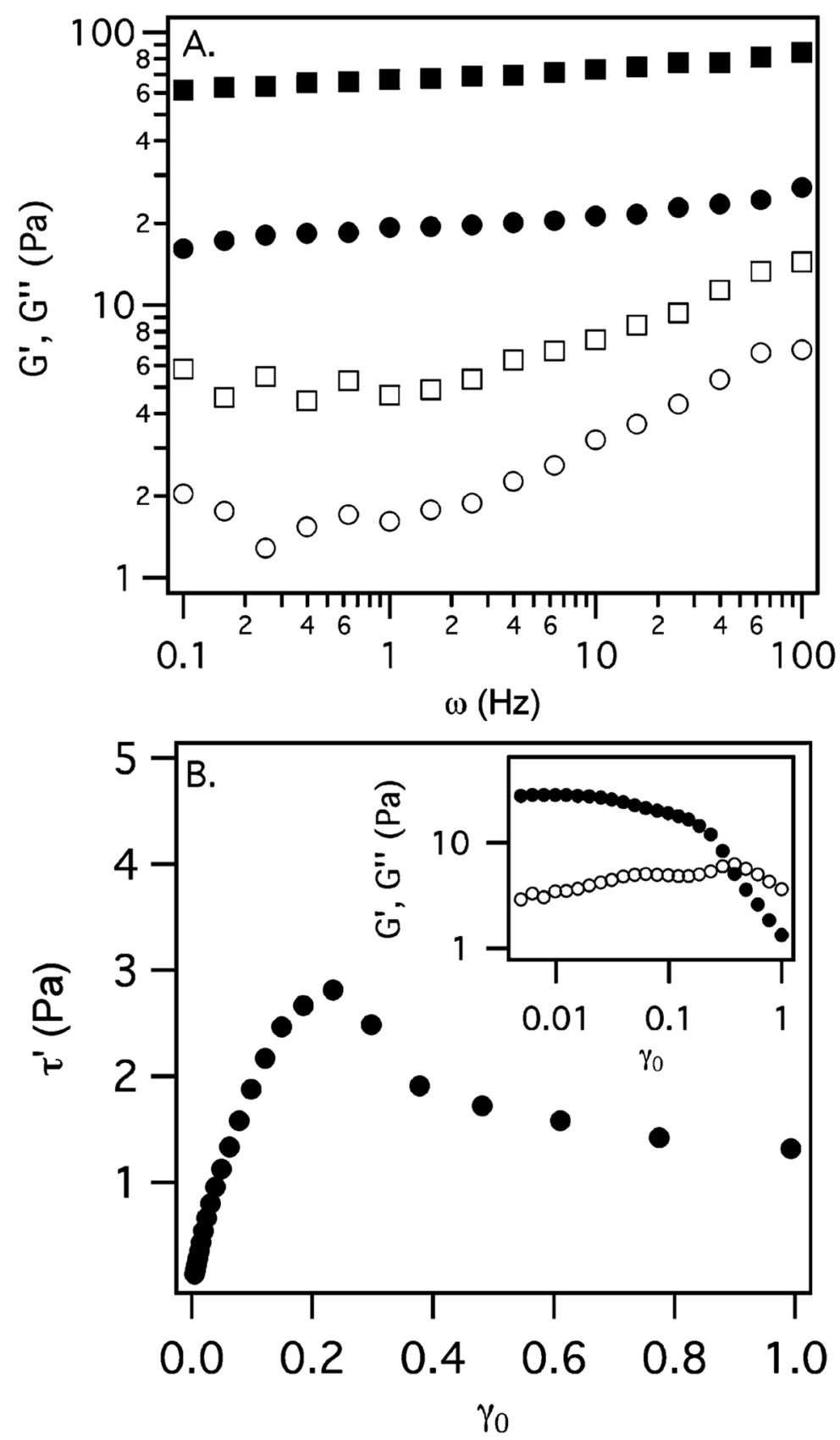

Figure 4.

(A) Bulk rheology of 2.5 (circles) and $7.1 \mathrm{wt} \%$ (squares) of 1. Closed and open symbols denote the storage $G^{\prime}(\omega)$ and loss $G^{\prime \prime}(\omega)$ moduli, respectively. (B) The in-phase stress component for $2.5 \mathrm{wt} \%$ of 1 versus the maximum strain shows the presence of a yield stress at approximately $2.8 \mathrm{~Pa}$ and $23 \%$ strain. Inset: Storage (closed symbols) and loss (open symbols) moduli over the entire range of strains measured. 


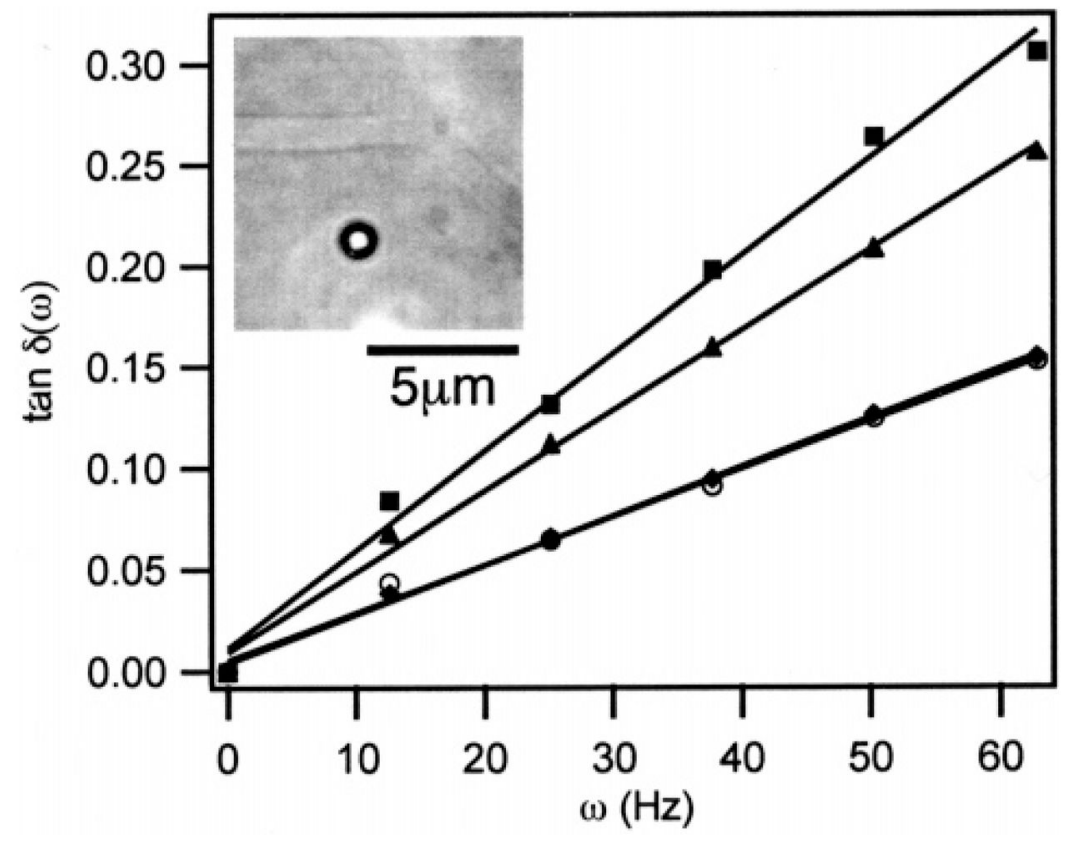

Figure 5.

Microheterogeneity of $\mathbf{1}$ is demonstrated via laser tweezer microrheology as a function of separtation from the filamentous structures observed via microscopy (inset). As the probe particle is brought closer to the structure, the slope of the phase lag with frequency increases from a viscous response identical to the buffer (circles and diamonds) to a response that reflects the hydrodynamic resistance of the microstructure (squares and triangles). The apparent viscosities are $1.1 \pm 0.1 \mathrm{mPa}$ s (circles and diamonds), $3.9 \pm 0.1 \mathrm{mPa}$ s (triangles), and $4.8 \pm$ $0.2 \mathrm{mPa}$ s (squares). 

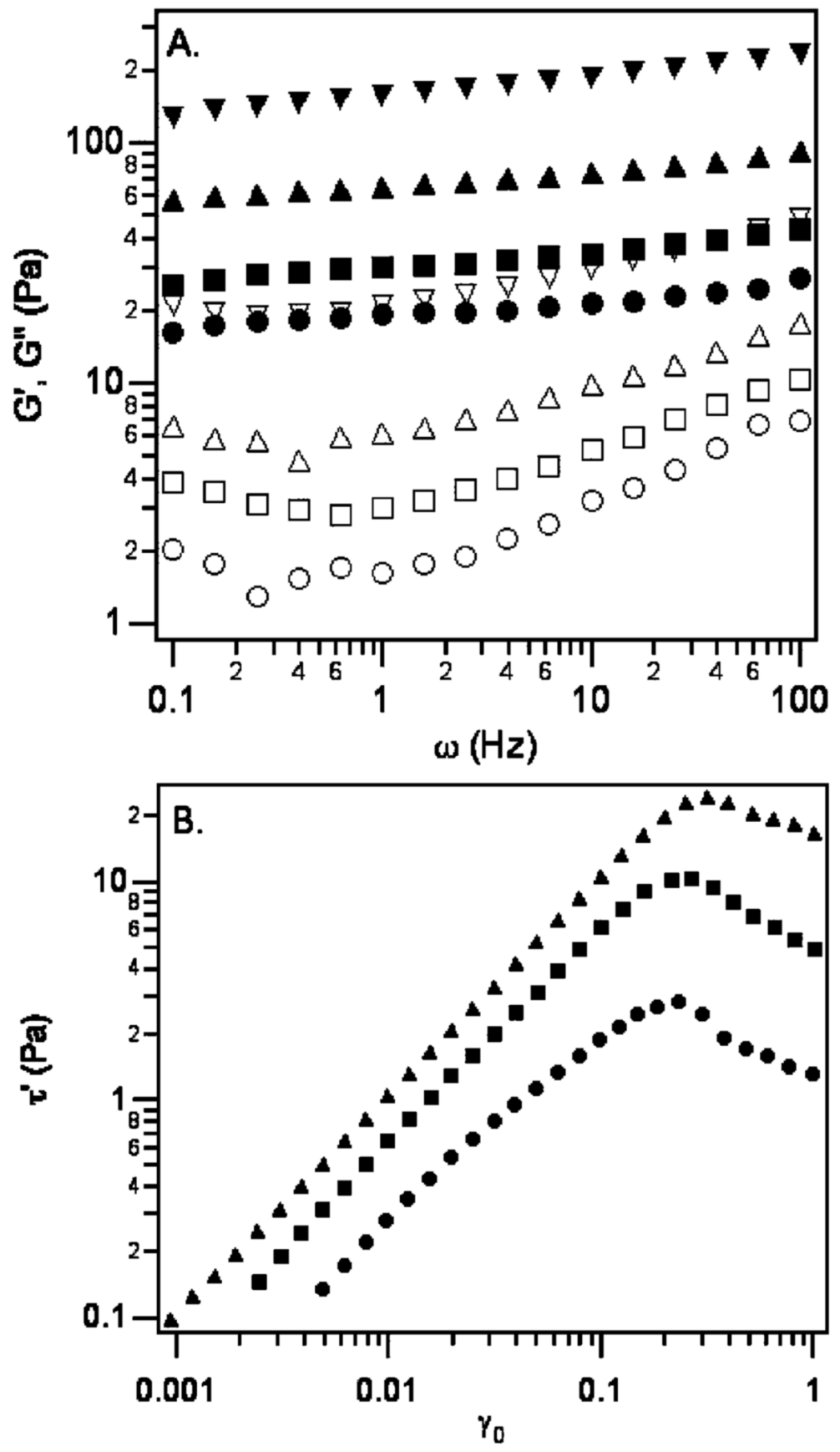

Figure 6.

(A) Storage moduli (closed symbols) and loss moduli (open symbols)of 4a for 9:1 (squares), 8:2 (triangles) and 6:4 (inverted triangles) molar ratios LMWH to ATIII. The response of 2.5 wt $\%$ of 1 (circles) is shown for comparison. (B) The in-phase stress component for 9:1 (squares) and 8:2 (triangles) samples plotted versus the maximum strain shows an increase in the yield stress compared with 1 (circles). 


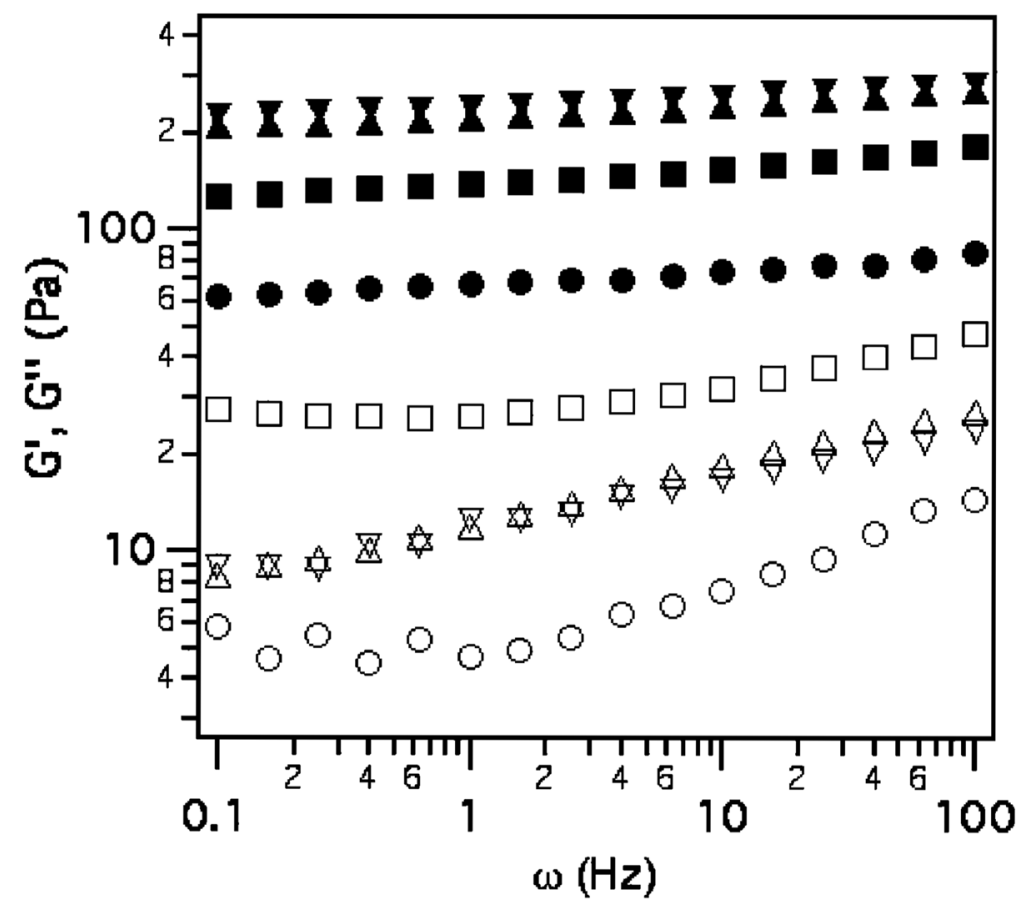

Figure 7.

Storage moduli (closed symbols) and loss moduli (open symbols) of $\mathbf{4 b}$ for 9:1 (squares), 8:2 (triangles) and 6:4 (inverted triangles) molar ratios of LMWH to HIP. The response of $7.1 \mathrm{wt}$ $\%$ of $\mathbf{1}$ (circles) is shown for comparison. 


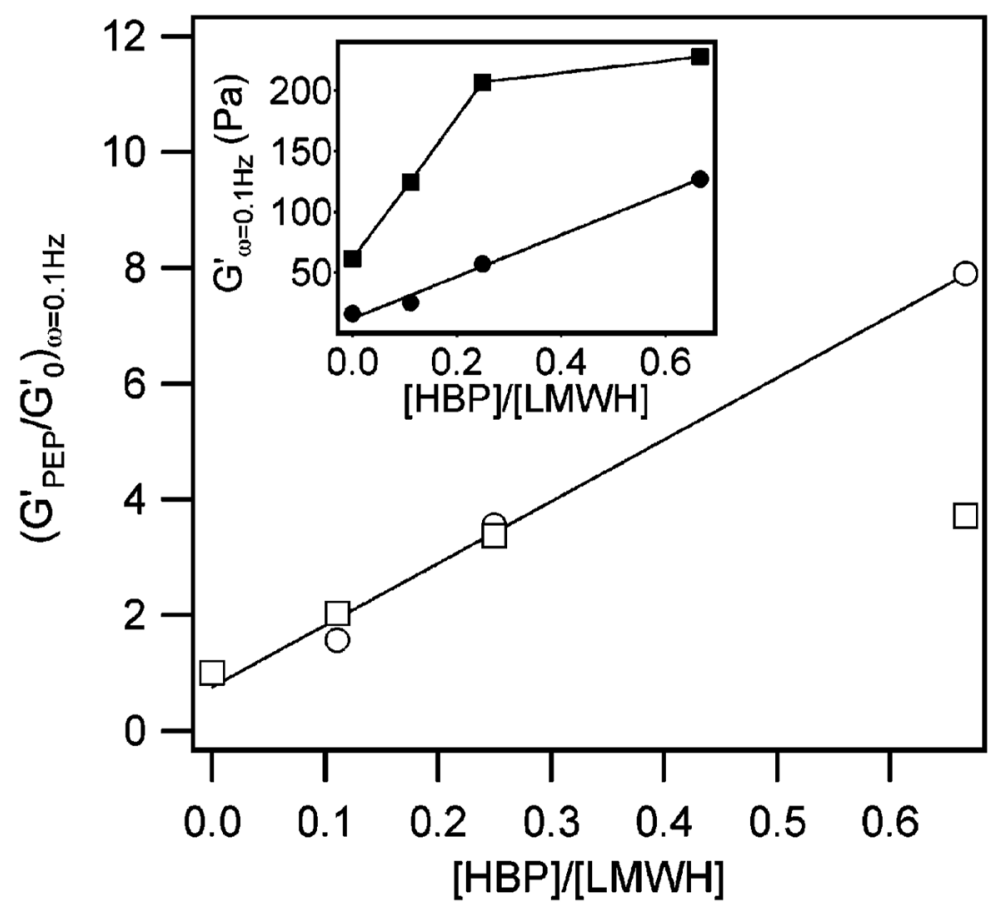

Figure 8.

Effect of adding 3 to 1 on the storage modulus, $G^{\prime}(\omega=0.1 \mathrm{~Hz})$, plotted as a function of the ratio of HBP (ATIII or HIP) to LMWH in the sample. The absolute magnitudes of $G^{\prime}(\omega=0.1$ $\mathrm{Hz}$ ) are shown in the inset for $\mathbf{3 a}$ (circles) and $\mathbf{3 b}$ (squares) samples. The curves collapse onto a single curve when normalized to the modulus for $\mathbf{1}$. 
Table 1

Heparin Binding Affinity Data for Heparin-Binding Peptides

\begin{tabular}{lcrr}
\hline peptide & $\begin{array}{c}\text { salt concentration for elution } \\
\text { from heparin column }(\mathbf{m M})\end{array}$ & $\boldsymbol{k}_{\mathbf{a}}\left(\mathbf{M}^{-\mathbf{1}} \mathbf{s}^{-\mathbf{1}}\right)^{\boldsymbol{a}}$ from SPR & $\boldsymbol{k}_{\mathrm{d}}\left(\mathbf{s}^{-\mathbf{1}}\right)^{\boldsymbol{a}}$ from SPR \\
& & & $\boldsymbol{K}_{\mathrm{D}}(\boldsymbol{\mu} \mathrm{M}) \boldsymbol{a}_{\text {from SPR }}$ \\
\hline ATIII & $594 \pm 2$ & $1.56 \pm 0.06 \times 10^{2}$ & $2.0 \pm 0.3 \times 10^{-3}$ \\
HIP & $687 \pm 1$ & $1.10 \pm 0.08 \times 10^{3}$ & $4.64 \pm 0.02 \times 10^{-3}$ \\
\hline
\end{tabular}

${ }^{a}$ Average of duplicate measurements. 